\title{
Editorial: Grid Connection of Converters in Renewable Applications
}

\author{
Fernando Martinez-Rodrigo ${ }^{1 *}$, Nicola Delmonte ${ }^{2}$, Alexis B. Rey-Boué ${ }^{3}$ and \\ N. F. Guerrero-Rodriguez ${ }^{4}$
}

${ }^{1}$ Electronics Technology Department, University of Valladolid, Valladolid, Spain, ${ }^{2}$ Department of Architecture and Engineering, University of Parma, Parma, Italy, ${ }^{3}$ Departamento de Electrónica, Tecnología de Computadoras y Proyectos, Universidad Politécnica de Cartagena, Cartagena, Spain, ${ }^{4}$ School of Mechanical and Electrical Engineering, Pontificia Universidad Católica Madre y Maestra PUCMM, Santo Domingo, Dominican Republic

Keywords: distributed power generation, microgrids, power grids, PWM invertors, renewable energy sources

\section{Editorial on the Research Topic}

\section{Grid Connection of Converters in Renewable Applications}

Energy generated from renewable sources is fed into the grid by means of electronic power converters. These can be supervised at system (grid) level to coordinate all productions points together with storages and loads. Regulations impose power supply quality requirements regarding harmonics, grid fault response and low voltage ride through (LVRT). The progress of distributed generation presents challenges to converters such as island mode operation, voltage and frequency regulation, simulation, etc. New collaborative solutions for "more smart" microgrids must be included to improve power quality, reliability, service quality and duty.

Wind turbines employing double-fed induction generators (DFIG) use two converters, one for the rotor side and one for the generator side. To improve the performance during severe grid failures, in Okedu and Barghash the advantages of using alternative configurations to the two-

\section{OPEN ACCESS}

Edited and reviewed by: ZhaoYang Dong, University of New South Wales, Australia

*Correspondence: Fernando Martinez-Rodrigo fernando.martinez@uva.es

Received: 30 July 2021 Accepted: 21 September 2021 Published: 06 October 2021

Citation:

Martinez-Rodrigo F, Delmonte $N$ Rey-Boué $A B$ and

Guerrero-Rodríguez NF (2021)

Editorial: Grid Connection of

Converters in Renewable Applications.

Front. Energy Res. 9:750454.

doi: 10.3389/fenrg.2021.750454 level converter, such as the parallel interleaved 2-level inverter, and the 3-level inverter, have been investigated. It has also been investigated to replace the classical dq-PLL with a new PLL, and to include a series dynamic braking resistor (SDBR) between the converters and the threephase connections.

Wind turbines must meet strict requirements, in terms of their behavior, in the event of grid failures, which are regulated by the LVRT regulations in each country. These regulations indicate, by means of voltage and time graphs, how long the wind turbines must remain connected depending on the depth of the faults. In addition, the limits of active and reactive power that can be exchanged during faults are established. The aim is to avoid cascading disconnections of wind turbines that would compromise the stability of the grid. In Okedu and Barghash, the effect of various elements in improving the behaviour of a DFIG against grid faults has been investigated. The first of these elements is the parameters of the IGBTs, concluding that the on-resistance has the greatest influence. The second is the use of a new PLL, and the third is the use of a SDBR during a grid failure. It was found that all of them could improve the performance of the generator in the event of a grid failure.

When a wind turbine uses a permanent magnet synchronous generator (PMSG), $100 \%$ of the energy generated passes through both converters. In Okedu and Barghash, the control systems of the generator-side and grid-side converters have been considered; several scenarios regarding the turn on resistance of the IGBTs have been considered, and their behaviour during grid faults has been 
analysed. Generator performance has also been studied with and without the use of a DC-DC converter for overvoltage protection.

The main generators used in wind turbines are DFIG and PMSG. In Okedu et al., a comparison of the behaviour of both wind turbines against grid faults has been carried out in various scenarios with different values of generator parameters.

The number of converters, associated with renewable generation, connected to the grid has increased significantly lately. This can affect the dynamic response, especially during disturbances, but it can also provide new grid support functionalities if information on the oscillation characteristics is available. Through the use of artificial intelligence, in Baltas et al. the abilities to predict and damp electromechanical oscillations have been improved.

With the constant increase in the number of wind turbines connected to the grid, it is very important to have the ability to maintain grid frequency control. In Okedu and Barghash, a work has been presented to stabilise the wind farm during periods of wind speed change by using capacitors connected via a DC-DC converter and a grid-connected DC-AC converter. It was concluded that higher values of the DC-DC converter time constant lead to better performances during load transients. A system including two steam turbines and two squirrel cage induction generators was used in the experiments.

Microgrids bring power generation closer to the places of consumption to reduce the saturation of distribution lines. They consist of renewable generation, energy storage and fossil fuel generation. They have three levels of control, where the primary level is the closest to the converters, and the tertiary level, the most external and slowest, performs general monitoring functions. The paper (Buraimoh et al.) focuses on the secondary control functions related to grid failure performance. It proposes a distributed control between inverters and is based on fast detection techniques (fast Delayed Signal Cancellation, DSC), with the objective of a fast control of active and reactive power. A robust transition method between fault mode and normal mode is proposed. Accurate coordination and power sharing between distributed energy resources is achieved.

Some energy conversion systems are so complex that they are very difficult to build and test in the laboratory. These include the study of high voltage direct current (HVDC) transmission when several modular multilevel converters (MMC) are involved together with DC grid failure protection elements. In Wang et al., a system including a simulated part (two digitally simulated MMC) and a physical part (two MMC) has been experimented with. The coupling between the two parts has been carried out by means of $\mathrm{A} / \mathrm{D}$ and $\mathrm{D} / \mathrm{A}$ converters and power amplifiers.

\section{AUTHOR CONTRIBUTIONS}

FM-R wrote the first version of the paper. ND, AR-B and NG-R corrected the paper.

Conflict of Interest: The authors declare that the research was conducted in the absence of any commercial or financial relationships that could be construed as a potential conflict of interest.

Publisher's Note: All claims expressed in this article are solely those of the authors and do not necessarily represent those of their affiliated organizations, or those of the publisher, the editors and the reviewers. Any product that may be evaluated in this article, or claim that may be made by its manufacturer, is not guaranteed or endorsed by the publisher.

Copyright (C) 2021 Martinez-Rodrigo, Delmonte, Rey-Boué and Guerrero-Rodríguez. This is an open-access article distributed under the terms of the Creative Commons Attribution License (CC BY). The use, distribution or reproduction in other forums is permitted, provided the original author(s) and the copyright owner(s) are credited and that the original publication in this journal is cited, in accordance with accepted academic practice. No use, distribution or reproduction is permitted which does not comply with these terms. 